\title{
Towards an Active Aging Society Based on Information and Communication Technology
}

\author{
Meei-Ying Kao ${ }^{1}$ and Chyi-In Wu ${ }^{2 *}$ \\ ${ }^{1}$ Graduate Institute of Humanities in Medicine, Taipei Medical University, Taiwan \\ ${ }^{2}$ Institute of Sociology, Academia Sinica, Taiwan \\ ${ }^{\star}$ Corresponding author: Dr. Chyi-In Wu, Institute of Sociology, Academia Sinica, Taiwan; E-mail: sss1ciw@gmail.com
}

Received: March 27, 2021; Accepted: April 06, 2021; Published: April 08, 2021

With the development of medicine and technology, the life expectancy of people, nowadays, is getting longer than several decades ago. Aging society is progressively emerging. More and more nations in the world have steadily moved towards an aging society or even a super-aged society. Obviously, the arrival of the Tsunami of the Aged people could result in national vibrations at various levels that eventually would have a major impact upon the global economy, society and politics.

"Aging" is not mainly a physiological process, but also a social and cultural manner. Aging is traditionally regarded as a physiological development with biological function and physical system progressively failure. However, it is ordinarily accompanied by changes in mental and social conditions. In addition to the phenomenon of aging that occurs inside the individual, the stimulus of the external environment also affects the speed and level of aging. The World Health Organization (WHO) has proposed the concept of "active aging" in its 2002 Report of Active Ageing: A Policy Framework. This landmark document drew attention to:

the fact that population aging was the product of two converging trends: more and more people living to be old at the same time dramatic decreases were occurring in fertility rates; that population aging was to occur in both the developed and the developing worlds; and that if it was to be a positive experience for countries and individuals, "longer life must be accompanied by continuing opportunities for health, participation and security" [1].

Essentially, it is derived from the concept of successful aging and has increasingly developed as productive aging and healthy aging. The goal is to build a society more compatible with the increase in the elderly population and the advent of the aging society. According to the widely accepted WHO definition of active aging, it is the process of optimizing opportunities for health, participation, and safety in order to promote the quality of life of people in old age. The definition is echoing the WHO's definition of health, a state of complete physical, mental, and social well-being. This has ultimately become the main reference framework for many international organizations and countries around the world to formulate health policies for the elderly.

Today, entering the information age, the overall life and behavior patterns of human beings have correspondingly been profoundly affected by cyber power. The invention of computers, the use of the internet, the popularization of tablets and smartphones, and internet usage and so on is evenly connected to the lives of the elderly. Surprisingly and beyond anyone's imagination, elder people are affected by the internet as much as the young generations do. Based on empirical research findings that through the use of information technology could not only shorten the unapproachability between people [2] and decrease loneliness [3] but also moderate depression [4] and life stress [5]. Thus, it is important to have the elderly being supported through the internet and by the internet. Still, despite all the benefits, the elder people in any society are the sole group that exposed to the internet the least [6]. The main reason lies in the lack of information preparation, lack of manipulative ability, anxiety, and dehumanization of not accustomed to computers [7]. Further studies have found that most elderly people use the internet for telecommunication which plays an important role in their social functions [8]. Yet, some studies correspondingly have shown that there are still quite a few elderly people who refuse to use computers or those who give up halfway through their studies [9] due to frustration or anxiety.

Facing the era of the aging society, proper use of information technology and the internet can make up for the impact of interpersonal contacts decline and physical degradation. Technology has always been aimed at making people's lives more convenient. Under the current wave of continuous innovation in information technology, especially, in the area of Artificial Intelligence, exploring the ways to meet the technological needs of the elderly, the elderly can use technology and information capabilities to support their own independent livings and social interactions and assist in managing and providing care. In turn, it promotes the social, mental and physical health of the elderly, improves their quality of life, and achieves the goal of successful, healthy and active aging.

Together, advances in Artificial Intelligence and information technology have changed the ways we live, and promise a bright future for aging human beings. Through a literature review, this article intends to integrate the goal of active aging and the advance of Artificial Intelligence and information technology in a state-of-the-art manner. It configures out a conceivable tactic for the elderly to live a happier and healthier life based on the infrastructure of ICT. 


\section{References}

1. World Health Organization (2002) Active Aging-A policy framework. http:// whqlibdoc.who.int/hq/2002/WHO_NMH_NPH_02.8.pdf

2. Bobillier Chaumon ME, Michel C, Tarpin Bernard F, Croisile B (2014) Can ICT improve the quality of life of elderly adults living in residential home care units? From actual impacts to hidden artefacts. Behaviour \& Information Technology 33: 574-590.

3. Cotten SR, Anderson WA, McCullough BM (2013) Impact of internet use on loneliness and contact with others among older adults: cross-sectional analysis. Journal of Medical Internet Research 15: 39. [crossref]

4. Cotten SR, Ford G, Ford S, Hale TM (2012) Internet use and depression among older adults. Computers in Human Behavior 28: 496-499.
5. Wright KB (2000) Social support satisfaction, on-line communication apprehension, and perceived life stress within computer-mediated support groups. Communication Research Reports 17: 139-147.

6. Baker C (2013) A connection for all ages: Enabling the benefits of high-speed Internet access for older adults. AARP Public Policy Institute 79: 18.

7. Cutler SJ, Hendricks J, Guyer A (2003) Age differences in home computer availability and use. The Journals of Gerontology Series B: Psychological Sciences and Social Sciences 58: 271-S280. [crossref]

8. Hilt ML, Lipschultz JH (2004) Elderly Americans and the Internet: E-mail, TV news, information and entertainment websites. Educational Gerontology 30: 57-72.

9. Namazi KH, McClintic M (2003) Computer use among elderly persons in long-term care facilities. Educational Gerontology 29: 535-550.

\section{Citation:}

Kao MY, Wu CI (2021) Towards an Active Aging Society Based on Information and Communication Technology. Ageing Sci Ment Health Stud Volume 5(2): 1-2. 